\title{
Current situation of Leishmania infantum infection in shelter dogs in northern Spain
}

\author{
Guadalupe Miró*, Rocío Checa, Ana Montoya, Leticia Hernández, Diana Dado and Rosa Gálvez
}

\begin{abstract}
Background: Canine leishmaniosis (CanL) caused by Leishmania infantum is a widespread endemic disease in the Mediterranean basin, though, so far, the north of Spain has been considered a non-endemic area. The aim of the present study was to determine the prevalence of specific antibodies to L. infantum among stray dogs living in shelters in this area, and to evaluate the clinical status (both clinical signs and clinico-pathological abnormalities) of seropositive dogs. Besides L. infantum infection, the epidemiological role of variables like sex, breed and age was also assessed.

Methods: Over the year 2011 a cross-sectional study was conducted on a total of 418 stray dogs. A preliminary entomological survey was carried out using CDC-light traps. The chi-squared test was used to examine relationships between $L$. infantum seroprevalence and the remaining variables.

Results: The overall seroprevalence of $L$. infantum infection detected was 3\% in the Cantabrian coast. In Orense the seroprevalence was $35.6 \%$. In this latter region, the presence of sand fly, Phlebotomus perniciosus was also detected.

In general, seropositivity for $L$. infantum was related to size (large breed dogs versus small) and age, with a significantly higher seroprevalence recorded in younger (0-3 years) and older dogs ( $>7$ years) than adult dogs. Clinical signs of CanL were observed in $41.3 \%$ of the seropositive dogs. The seropositivity for L. infantum infection associated with the presence of clinical signs and/or abnormal laboratory findings shows a prevalence of $4.5 \%$.

Conclusion: Our data provide new insight into the prevalence of CanL across northern Spain. The situation observed in Orense seems to be worsening compared to the few reports available, with figures being similar to those cited for known endemic areas of Spain. Besides, the presence of $P$. perniciosus in Orense points out to a risk of the spread of this zoonotic disease in this geographical area. These findings identify a need for an active search for the sand fly vectors of $L$. infantum across the entire northern spanish region including the rest of Galicia, Asturias, Cantabria and the Basque Country.
\end{abstract}

\section{Background}

Canine leishmaniosis (CanL) is a widespread endemic disease in the Mediterranean basin. Its primary causative agent, Leishmania infantum, is transmitted to humans and animals by blood-sucking phlebotomine sand flies [1]. Dogs are the main domestic reservoir for human infection by L. infantum [2].

A risk of the introduction of L. infantum infection in northern Europe is supported by the idea that changing factors linked to climate and environment could determine the expansion of the current geographical

\footnotetext{
* Correspondence: gmiro@vet.ucm.es

* Correspondence: gmiro@vet.ucm.es Complutense, Madrid, Spain
} Complutense, Madid, Spain

C 2012 Miró et al; licensee BioMed Central Ltd. This is an Open Access article distributed under the terms of the Creative Commons Biomed Central Attribution License (http://creativecommons.org/licenses/by/2.0), which permits unrestricted use, distribution, and reproduction in any medium, provided the original work is properly cited. also been attributed an important role in the spread of leishmaniosis towards the north of Europe [7-9]. In Germany, it has been estimated that some 20,000 infected dogs have been imported by tourists from endemic zones in southern Europe [7]. The presence of reservoirs and the detection of one of the parasite's main vectors, Phlebotomus perniciosus, in central European countries, such as Switzerland [10] or Germany [11], suggest the possible emergence of the disease at latitudes where it did not traditionally exist [12-14]. In effect, the distribution range of leishmaniosis across the European continent is no longer limited to the Mediterranean basin distribution range of the disease and its vectors [3-6]. 
and, recently, new disease foci have been detected at the foothills of mountain ranges such as the Alps $[15,16]$ or Pyrenees [17].

Estimates of canine L. infantum infection seroprevalence reported for Spain range from 3.7\% for Orense province in the northwest corner of the country [18] to $34.6 \%$ for Málaga province on the south coast [19]. Northern Spain is presently considered a non-endemic area despite the sparse survey data available [18]. Recent works have reported the detection of CanL and its sand fly vectors, Phlebotomus ariasi and P. perniciosus, in a Pyrenean area of northeast Spain where the disease was previously unknown [20,21]. In Italy, the results of a recent study revealed the northward spread of CanL to a kennel in northern Italy, not previously affected by native infection foci [22]. Collectively, these observations suggest that knowledge of the real status of this disease in areas up until recently considered disease-free will help design control and prevention programmes with the final aim that veterinarians in these regions include CanL in their list of differential diagnosis tests.

The present study was designed to assess the status of L. infantum infection in northern Spain by examining dogs housed in six animal protection shelters across this large region. A preliminary sand fly survey was also conducted in the area of study.

\section{Methods}

\section{Study area}

The dogs examined were housed in kennels at six shelters, belonging to an animal protection organization, along the Cantabrian coast (northern Spain) and Orense. Climate and vegetation are typically oceanic, with warm summers and cool winters and rainfall evenly distributed all year round.

The shelters are located in Torrelavega (Cantabria); Gijón -Serín and Poago- and Langreo (Asturias), Orense (Galicia) and Santurce (Biscay) (Figure 1). These animal shelters are ideal for this type of study since they are situated in rural areas and the dogs live outdoors where they are exposed to the bites of hematophagous arthropods including phlebotomine sand flies. At these shelters, the animals were sterilized and maintained on a health control programme. The dogs were kept and handled according to the animal welfare standards upheld by Universidad Complutense de Madrid.

The characteristics of the six centres varied greatly. Thus, at the shelter in Torrelavega, some of the dogs were kept in individual huts with soil bedding and the rest were housed in groups of 3-5 dogs in covered open kennels without walls. At the shelters in Asturias (Gijón and Langreo) and Biscay (Santurce) all dogs were kept in groups of 4-5 dogs per kennel. Each kennel with a concrete floor had an indoor and outdoor area. In the animal shelter at Orense, the dogs were kept outside in yards (approximately 30-40 animals per yard) depending on the size and sex of the dogs.

\section{Data collection}

Over the year 2011, our cross-sectional study was conducted on a total of 418 stray dogs from Torrelavega (Cantabria); Gijón -Serín and Poago- and Langreo (Asturias); Orense (Orense) and Santurce (Biscay) (Table 1).

From each dog, a 5-6 ml blood sample was obtained by cephalic venipuncture. The collected blood was placed in four tubes containing: (1) lithium heparin (1 $\mathrm{ml}$ ) for biochemical profile; (2) EDTA $(0.5 \mathrm{ml})$ for full blood counts and blood smears; (3) EDTA (1 ml) to detect other CBVD (canine-borne vector diseases) by PCR; and (4) a tube without additives $(2-3 \mathrm{ml}$ ) for antibody testing. The blood samples were kept at $4^{\circ} \mathrm{C}$ until processing and those mixed with EDTA for PCR were stored frozen at $-80^{\circ} \mathrm{C}$ for a future epidemiological study. In addition, a clinical score was awarded to each dog in a thorough physical exam, evaluating both clinical signs and laboratory abnormalities (Table 2). We also took a picture of each animal and recorded the variables name, age, breed, sex, weight, and travelling history whenever possible.

\section{Laboratory tests}

Serological testing for L. infantum consisted of detecting specific antibodies using the indirect immunofluorescence antibody test (IFAT) against in-house cultured promastigotes. Seroprevalence was calculated as the percentage of dogs testing positive for L. infantum antibodies. The serial dilutions prepared were ranged from $1 /$ 25 to $1 / 6400$. The IFAT for anti-Leishmania-specific immunoglobulin G (IgG) antibodies was performed as described previously [23] using a cut-off $\geq 1: 100$ to denote seropositivity.

\section{Preliminary entomological survey}

A preliminary entomological survey was carried out in September 2011 using CDC-light traps in Orense. Over two consecutive days, four CDC-light traps were set up in the afternoon and recovered early in the morning. Traps were placed no further than $3 \mathrm{~m}$ from the kennel. The animal shelter in Orense is near a small stream with riverside vegetation.

\section{Statistical analysis}

Seropositivity frequencies were compared according to age, sex, and dog size (Table 3 ). The chi-squared test was used to examine relationships between L. infantum seroprevalence and the remaining variables. Differences were considered significant at $\mathrm{p} \leq 0.05$. All statistical 


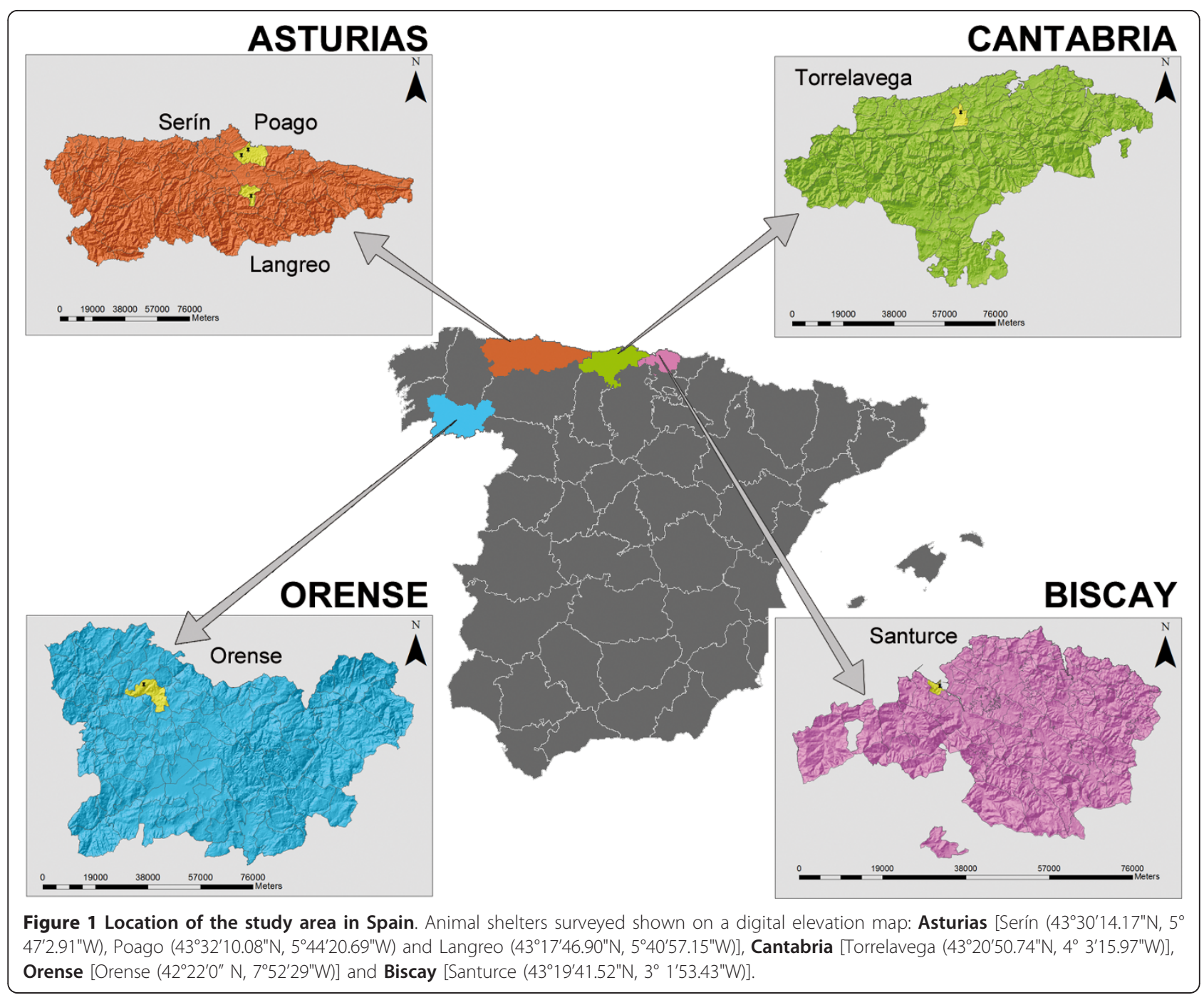

tests were performed using SPSS 19.0 software (SPSS Inc., Chicago, IL, USA).

\section{Results}

Over the year 2011, 418 stray dogs were examined in four regions of northern Spain. Using the cut-off of a $L$. infantum antibody titre $\geq 1: 100$ to denote seropositivity, seroprevalences for the different regions were: Cantabria $2 \%$ (2 out of 100 ), Asturias $4.7 \%$ (8 out of 171 ), Orense

Table 1 Leishmania infantum seroprevalence by locality

\begin{tabular}{lccc}
\hline Locality & Total & $\begin{array}{c}\text { Seropositivity }(\geq 1: 100) \\
\mathbf{N}(\%)\end{array}$ & $\begin{array}{c}\text { Low titre } \\
(\mathbf{1 / 5 0}) \\
\mathbf{N}(\%)\end{array}$ \\
\hline Torrelavega & 100 & $2(2)$ & $8(8)$ \\
Serín, Poago and Langreo & 171 & $8(4.7)$ & $7(4.1)$ \\
Orense & 101 & $36(35.6)$ & $23(22.7)$ \\
Santurce & 46 & $0(0)$ & $2(4.3)$ \\
\hline
\end{tabular}

35.6\% (36 out of 101) and Biscay 0\% (0 out of 47). Antibody titres recorded in seropositive animals ranged from $1 / 100$ to $1 / 3200$. Clinical signs compatible with CanL were observed in nineteen seropositive dogs, so the seroprevalence of $L$. infantum in clinically healthy and sick dogs was $58.7 \%$ (27/46) and 41.3\% (19/46), respectively.

In general, antibody titres showed positive correlation with clinical scores, such that animals with higher clinical scores revealed higher antibody titres $(\geq 1 / 400)$ (Table 4). Of note, among the animals exhibiting low antibody titres (along with low clinical scores), dog OR100 (see Table 4) had a high clinical score suggesting some other underlying disease or coexisting infection.

The age of the dogs ranged from 4 months to 13 years. When the dogs were stratified into three categories: young $(<3$ years), adult $(3 \leq$ years $<7)$ and older dogs ( $\geq 7$ years), significant differences were observed in L. infantum seroprevalence $(p=0.036)$. These differences were observed both between adult and young 
Table 2 Scoring system categories based on clinical signs and clinic-pathological findings

\begin{tabular}{|c|c|c|c|}
\hline CLINICAL SIGNS & 0 & 1 & 2 \\
\hline Weight & normal & reduced & cachexia \\
\hline Appetite & normal & reduced & anorexia \\
\hline Behaviour & normal & apathy & postration \\
\hline Lymphadenomegaly & absent & localized & generalized \\
\hline Epistaxis & absent & moderate & severe \\
\hline Keratoseborreic cutaneous lesions & absent & moderate & generalized \\
\hline Ulcerative lesions & absent & simple & multiple \\
\hline Onicogriphosis & absent & moderate & severe \\
\hline Ocular lesions & absent & moderate & severe \\
\hline Digestive disorders & absent & mild & severe \\
\hline Arthropathy & absent & simple & multiple \\
\hline Amyotrophy & absent & moderate & severe \\
\hline CLINICO-PATHOLOGICAL FINDINGS & 0 & 1 & 2 \\
\hline Plasma proteins & normal & elevated & reduced \\
\hline A/G ratio & normal & reduced & - \\
\hline Urea & normal & reduced & - \\
\hline Creatinine & normal & elevated & - \\
\hline ALT & normal & elevated & - \\
\hline Complete blood count & \multicolumn{3}{|c|}{$0=$ normal $1=$ abnormal } \\
\hline
\end{tabular}

dogs $(p=0.015)$ and between adult and older dogs $(p=$ 0.024 ), the adult group differing significantly from the other two groups. Hence, age exhibited a bimodal distribution of seroprevalence with a peak in young dogs and a second larger peak observed in the older dogs.

Table 3 Leishmania infantum seroprevalence by age, sex and size

\begin{tabular}{lccc}
\hline & Total & Seropositive (N) & Seroprevalence (\%) \\
\hline Age (years) & & & \\
$\leq 3$ & 153 & 21 & 13.7 \\
$3-7$ & 147 & 8 & $5.4^{*(1)}$ \\
$\geq 7$ & 111 & 15 & 13.5 \\
\hline Sex & & & \\
$\quad$ Males & 211 & 23 & 10.9 \\
$\quad$ Females & 204 & 23 & 11.3 \\
\hline Size (kg) & & & \\
$\quad$ Small $(\leq 15)$ & 97 & 5 & $5.2^{*(2)}$ \\
$\quad$ Medium (15-25) & 79 & 7 & 8.8 \\
$\quad$ Large $(\geq 25)$ & 216 & 30 & 13.8 \\
\hline P & &
\end{tabular}

* $p \leq 0.05$

(1) These differences were observed between adult and young dogs ( $p=$ $0.015)$ and between adult and older dogs ( $p=0.024)$; (2) Significant differences were detected between small breed size compared to a large breed size $(p=0.023)$.
Table 4 Clinical scores recorded in the seropositive dogs

\begin{tabular}{|c|c|c|}
\hline DOG NUMBER & IFAT Leishmania & CLINICAL SCORING \\
\hline OR 4 & $1 / 100$ & 0 \\
\hline OR 8 & $1 / 800$ & 4 \\
\hline OR 10 & $1 / 1600$ & 11 \\
\hline OR 19 & $1 / 100$ & 0 \\
\hline OR 22 & $1 / 200$ & 1 \\
\hline OR 30 & $1 / 200$ & 0 \\
\hline OR 43 & $1 / 800$ & 0 \\
\hline OR 44 & $1 / 200$ & 2 \\
\hline OR 46 & $1 / 3200$ & 6 \\
\hline OR 47 & $1 / 200$ & 4 \\
\hline OR 48 & $1 / 100$ & 0 \\
\hline OR 51 & $1 / 100$ & 0 \\
\hline OR 52 & $1 / 200$ & 2 \\
\hline OR 54 & $1 / 200$ & 4 \\
\hline OR 56 & $1 / 400$ & 0 \\
\hline OR 57 & $1 / 200$ & 2 \\
\hline OR 60 & $1 / 200$ & 0 \\
\hline OR 62 & $1 / 200$ & 5 \\
\hline OR 65 & $1 / 400$ & 0 \\
\hline OR 67 & $1 / 200$ & 2 \\
\hline OR 69 & $1 / 200$ & 5 \\
\hline OR 70 & $1 / 400$ & 0 \\
\hline OR 72 & $1 / 200$ & 0 \\
\hline OR 74 & $1 / 400$ & 6 \\
\hline OR 77 & $1 / 800$ & 0 \\
\hline OR 80 & $1 / 200$ & 0 \\
\hline OR 83 & $1 / 3200$ & 3 \\
\hline OR 84 & $1 / 800$ & 6 \\
\hline OR 85 & $1 / 400$ & 0 \\
\hline OR 88 & $1 / 200$ & 0 \\
\hline OR 94 & $1 / 400$ & 15 \\
\hline OR 95 & $1 / 200$ & 2 \\
\hline OR 98 & $1 / 200$ & 4 \\
\hline OR 99 & $1 / 100$ & 0 \\
\hline OR 100 & $1 / 100$ & 9 \\
\hline OR 101 & $1 / 100$ & 0 \\
\hline AS 18 & $1 / 100$ & 0 \\
\hline AS 72 & $1 / 100$ & 0 \\
\hline AS 100 & $1 / 100$ & 3 \\
\hline AS 139 & $1 / 100$ & 0 \\
\hline AS 141 & $1 / 100$ & 0 \\
\hline AS 142 & $1 / 100$ & 0 \\
\hline AS 152 & $1 / 100$ & 2 \\
\hline AS 162 & $1 / 100$ & 0 \\
\hline SA 36 & $1 / 100$ & 0 \\
\hline SA 61 & $1 / 100$ & 2 \\
\hline
\end{tabular}

${ }^{*} \mathrm{OR}=$ Orense; $\mathrm{AS}=$ Asturias; $\mathrm{SA}=$ Santander (Cantabria) 
Significant differences in CanL infection risk were detected by breed according to size $(p=0.023)$. Thus, a small breed size was a protective factor compared to a large breed size. In addition, the seroprevalence recorded in females $(10.9 \%)$ was slightly lower than in males $(11.3 \%)$ and not significant $(p=0.903)$.

In our preliminary study conducted in Orense, eight sand flies were collected using CDC-light traps. All were identified as $P$. perniciosus. One male and one female were captured on September $26^{\text {th }} 2011$, and four males and two females on September $27^{\text {th }} 2011$.

\section{Discussion}

The seroprevalence of $L$. infantum in Spain varies across a geographical gradient (3.7 - 34.6\%), with highest prevalences cited for southern and eastern Spain (Mediterranean coast) [19]. Despite the detection of CanL in a Pyrenean area of northeast Spain where the disease was previously unknown [20,21], its substantially low prevalence in the north of the country (3.7-4.4\%) has earned the consideration of this region so far as a low endemic area [18]. Similar seroprevalences were recorded in the present study performed in Asturias, Biscay and Cantabria $(0-4.7 \%)$, in which the presence of $L$. infantum was detected in two out off three shelters of sampled dogs. On the other hand, the seroprevalence observed in Orense $(35.6 \%)$ constitutes a considerable increase over this latest reported estimate [18] similar to the figures quoted for Spanish areas classed as endemic. Amusategui et al. (2004) detected a similarly high seroprevalence (29.2\%) of L. infantum in Valdeorras, a town close to our Orense sampling site. Probably, the current bioclimatic characteristics of this geographic area are compatible with the presence and transmission of L. infantum according to the prediction models described for other regions in Europe [24-26]. Effectively, the preliminary data obtained in the present study demonstrate the presence of $P$. perniciosus in the area of the animal shelter in Orense. Also P. perniciosus was found by other authors in Orense [27]. Moreover, P. ariasi was found in Galicia (Lugo and Orense) [28,29]. We were unable to address the presence of sand flies at the other animal shelters since the weather conditions were unsuitable for sand flies.

The dogs included in our study were 4 months to 13 years of age. L. infantum seroprevalence was higher in dogs aged $0-3$ years $(13.7 \%)$ or older than 7 years $(13.5 \%)$ than in those 3-7 years old (5.4\%). Thus, seroprevalence showed a bimodal distribution with a peak in dogs under 3 years and another peak between the ages of 8 and 10 years. This pattern suggests that L. infantum infection is dependent on host immunological status $[30,31]$. Similar data have been reported in a study conducted in Madrid, Spain [32], while other authors have only noted a higher prevalence in older dogs suggesting that susceptibility to $L$. infantum infection increase with age [31,33-35].

In our study, dog size emerged as an epidemiological variable related to L. infantum infection such that seroprevalence was significantly higher in the large breed dogs $(13.8 \%)$ compared to the small breed dogs (5.2\%), consistent with the results of others $[32,36]$. A possible explanation could be that the greater body mass of larger dogs determines a larger surface area exposed to bites of the arthropod vector, as suggested for other vector borne disease such as canine thelaziosis [37]. Alternatively, it could be that medium or large-sized dogs are those most used for farm activities requiring they remain outdoors for long periods of time [32].

Although in some cases a higher prevalence of leishmaniosis has been observed among male dogs [38], we detected no such link between L. infantum infection and sex (seroprevalence $10.9 \%$ in males versus $11.3 \%$ in females), as mentioned previously by other authors $[18,32,35,39]$.

Nineteen out of 46 seropositive dogs (41.3\%) showed clinical signs of CanL, mainly enlarged lymph nodes (13/46), skin lesions (17/46) and weight loss (14/46). However, the prevalence of $L$. infantum infection was higher in the clinically healthy dogs (58.7\%) than in those showing some of these signs (41.3\%). Similar observations have been made by others $[33,35,40]$. The high percentage of subclinical infection may suggest some level of cellular immune response developing over time, which is believed to limit disease outcome [41], or that these dogs were still in the early stages of disease since many clinically healthy seropositive dogs had low antibody titres (1/100). Thus, in Cantabria and Asturias all seropositive dogs had a titre of $1 / 100$ whilst in Orense only 7 of the 36 seropositive dogs had titres as low as $1 / 100$. In these particular dogs along with dogs showing 1/50 titres (see Tables 1 and 4), we will, in the early future, be determining subsequent antibody changes to assess their seroconversion and clinical status.

We should highlight that over $25 \%$ (13 out of 46 had no clinical signs nor abnormal laboratory findings) of the seropositive dogs were clinically healthy with titres of $1 / 100$. These dogs could pose a risk of infection aggravated by their non-ideal living conditions (affected by stress or concomittant diseases). It is especially important that this type of stray animal be monitored both in endemic and non endemic areas.

\section{Conclusions}

In conclusion, our findings reveal a low seroprevalence of $L$. infantum infection in stray dogs along the Cantabrian coast, on the contrary in the Orense province the 
prevalence was similar to that reported in endemic areas of Spain. The concurrent detection of $P$. perniciosus in Orense suggests a risk of the spread of this zoonotic disease, and prompts further studies designed to actively search for the sand fly vectors of CanL in nearby areas of Asturias, Cantabria and Biscay.

\section{Acknowledgements}

The authors are indebted to the staff of the animal protection shelters and veterinarians participating in this study. We thank Dr. Ricardo Molina for providing the CDC-light sand fly traps. We also thank Alba Bello for her support in the field trial.

Publication of the series CVBD7 was sponsored by Bayer Animal Health $\mathrm{GmbH}$.

\section{Authors' contributions}

GM designed the survey, drafted the first version of the manuscript and finalized the manuscript. RC, AM, LH and DD carried out the field survey and laboratory work and finalized the manuscript. RG performed the entomological study, drafted the first version of the manuscript and finalized the manuscript. AM, RG and RC performed the statistical analysis of data. All the authors reviewed the manuscript.

\section{Competing interests}

The authors declare that they have no competing interests.

Received: 10 January 2012 Accepted: 27 March 2012

Published: 27 March 2012

\section{References}

1. Rioux JA, Guilvard E, Gállego J, Moreno G, Pratlong F, Portús M, Rispail P, Gállego M, Bastien P: Phlebotomus ariasi Tonnoir, 1921 et Phlebotomus perniciosus Newstead, 1911 vecteurs du complexe Leishmania infantum dans un même foyer: Infestations par deux zymodèmes syntopiques. A propos d'une enquête en Catalogne (Espagne). In Leishmania Taxonomie et Phylogenèse Applications Éco-Épidemiologiques. Edited by: IMEEE. Montpellier; 1986:439-444.

2. Alvar J, Cañavate C, Molina R, Moreno J, Nieto J: Canine leishmaniasis. Adv Parasitol 2004, 57:1-88.

3. Ready PD: Leishmaniasis emergence in Europe. Euro Surveill 2010, 15:19505.

4. Dujardin JC, Campino L, Cañavate C, Dedet JP, Gradoni L, Soteriadou K, Mazeris A, Ozbel Y, Boelaert M: Spread of vector-borne diseases and neglect of Leishmaniasis, Europe. Emerg Infect Dis 2008, 14:1013-1018.

5. Reisen WK: Landscape epidemiology of vector-borne diseases. Annu Rev Entomol 2010, 55:461-483.

6. Palatnik-de-Sousa CB, Day MJ: One Health: the Global Challenge of Epidemic and Endemic Leishmaniasis. Parasit Vectors 2011, 4:197.

7. Naucke TJ, Menn B, Massberg D, Lorentz S: Sandflies and leishmaniasis in Germany. Parasitol Res 2008, 103(Suppl 1):S65-S68.

8. Semenza JC, Menne B: Climate change and infectious diseases in Europe. Lancet Infect Dis 2009, 9:365-375.

9. Menn B, Lorentz S, Naucke TJ: Imported and travelling dogs as carriers of canine vector-borne pathogens in Germany. Parasit Vectors 2010, 3:34.

10. Grimm F, Gessler M, Jenni L: Aspects of sandfly biology in southern Switzerland. Med Vet Entomol 1993, 7:170-176

11. Naucke TJ, Schmitt C: Is leishmaniasis becoming endemic in Germany? Int J Med Microbiol 2004, 293(Suppl 37):179-181.

12. Harms G, Schonian G, Feldmeier H: Leishmaniasis in Germany. Emerg Infect Dis 2003, 9:872-875.

13. Jacob D: Short communication on regional climate change scenarios and their possible use for impact studies on vector-borne diseases. Parasitol Res 2008, 103(Suppl 1):S3-S6.

14. Schroder W, Schmidt G: Spatial modelling of the potential temperaturedependent transmission of vector-associated diseases in the face of climate change: main results and recommendations from a pilot study in Lower Saxony (Germany). Parasitol Res 2008, 103(Suppl 1):S55-S63.
15. Maroli M, Rossi L, Baldelli R, Capelli G, Ferroglio E, Genchi C, Gramiccia M, Mortarino M, Pietrobelli M, Gradoni L: The northward spread of leishmaniasis in Italy: evidence from retrospective and ongoing studies on the canine reservoir and phlebotomine vectors. Trop Med Int Health 2008, 13:256-264.

16. Morosetti G, Bongiorno G, Beran B, Scalone A, Moser J, Gramiccia M, Gradoni L, Maroli M: Risk assessment for canine leishmaniasis spreading in the north of Italy. Geospat Health 2009, 4:115-127.

17. Dereure J, Vanwambeke SO, Male P, Martinez S, Pratlong F, Balard Y, Dedet JP: The potential effects of global warming on changes in canine leishmaniasis in a focus outside the classical area of the disease in southern France. Vector Borne Zoonotic Dis 2009, 9:687-694.

18. Amusátegui I, Sainz A, Aguirre E, Tesouro MA: Seroprevalence of Leishmania infantu in northwestern Spain, an area traditionally considered free of leishmaniasis. Ann N Y Acad Sci 2004, 1026:154-157.

19. Morillas F, Sánchez Rabasco F, Ocaña J, Martín-Sánchez J, Ocana-Wihelmi J, Acedo C, Sanchís-Marín MC: Leishmaniosis in the focus of the Axarquia region, Malaga province, southern Spain: a survey of the human, dog, and vector. Parasitol Res 1996, 82:569-570.

20. Ballart C, Alcover MM, Portus M, Gallego M: Is leishmaniasis widespread in Spain? First data on canine leishmaniasis in the province of Lleida, Catalonia, northeast Spain. Trans R Soc Trop Med Hyg 2011, 106:134-136.

21. Ballart C, Barón S, Alcover MM, Portus M, Gallego M: Distribution of phlebotomine sand flies (Diptera: Psychodidae) in Andorra: First finding of $P$. perniciosus and wide distribution of P. ariasi. Acta Trop 2011, 122:155-159.

22. Baldelli R, Piva S, Salvatore D, Parigi M, Melloni O, Tamba M, Bellini R, Poglayen G: Canine leishmaniasis surveillance in a northern Italy kennel. Vet Parasitol 2011, 179:57-61.

23. Mancianti F, Meciani N: Specific serodiagnosis of canine leishmaniasis by indirect immunofluorescence, indirect hemagglutination, and counterimmunoelectrophoresis. Am J Vet Res 1988, 49:1409-1411.

24. Franco AO, Davies CR, Mylne A, Dedet JP, Gallego M, Ballart C, Gramiccia M, Gradoni L, Molina R, Galvez R, et al: Predicting the distribution of canine leishmaniasis in western Europe based on environmental variables. Parasitology 2011, 138:1878-1891.

25. Fischer D, Thomas SM, Beierkuhnlein C: Temperature-derived potential for the establishment of phlebotomine sandflies and visceral leishmaniasis in Germany. Geospat Health 2010, 5:59-69.

26. Chamaille L, Tran A, Meunier A, Bourdoiseau G, Ready P, Dedet JP: Environmental risk mapping of canine leishmaniasis in France. Parasit Vectors 2010, 3:31, 5:59-69.

27. León Sanz CM, Collantes F, Martínez-Ortega E: Revisión de la colección Nájera de Flebotomos (Diptera, Psychodidae) depositada en el Museo Nacional de Ciencias Naturales de Madrid. Graellsia 1999, 55:217-221.

28. Gil Collado J, Morillas Marquez F, Sanchis Marin MC: [Phlebotomu in Spain]. Rev Sanid Hig Publica (Madr) 1989, 63:15-34.

29. Houin R: New locations of phlebotomi in Spain. Ann Parasitol Hum Comp 1965, 40:341-363.

30. Amela C, Méndez I, Torcal JM, Medina G, Pachón I, Cañavate C, Alvar J: Epidemiology of canine leishmaniasis in the Madrid region, Spain. Eur J Epidemiol 1995, 11:157-161.

31. Miranda S, Roura X, Picado A, Ferrer L, Ramis A: Characterization of sex age, and breed for a population of canine leishmaniosis diseased dogs. Res Vet Sci 2008, 85:35-38.

32. Gálvez R, Miró G, Descalzo MA, Nieto J, Dado D, Martín O, Cubero E, Molina R: Emerging trends in the seroprevalence of canine leishmaniosis in the Madrid region (central Spain). Vet Parasitol 2010, 169:327-334.

33. Cardoso L, Schallig HD, Neto F, Kroon N, Rodrigues M: Serological survey of Leishmani infection in dogs from the municipality of Peso da Regua (Alto Douro, Portugal) using the direct agglutination test (DAT) and fast agglutination screening test (FAST). Acta Trop 2004, 91:95-100.

34. Papadopoulou C, Kostoula A, Dimitriou D, Panagiou A, Bobojianni C, Antoniades G: Human and canine leishmaniasis in asymptomatic and symptomatic population in Northwestern Greece. J Infect 2005, 50:53-60.

35. Miró G, Montoya A, Mateo M, Alonso A, García S, García A, Caballero MJ, Molina R: A leishmaniosis surveillance system among stray dogs in the region of Madrid: ten years of serodiagnosis (1996-2006). Parasitology Res 2007, 101:253-257. 
36. Martín-Sánchez J, Morales-Yuste M, Acedo-Sánchez C, Barón S, Díaz V, Morillas-Márquez F: Canine leishmaniasis in southeastern Spain. Emerg Infect Dis 2009, 15:795-798.

37. Miro G, Montoya A, Hernandez L, Dado D, Vazquez MV, Benito M, Villagrasa M, Brianti E, Otranto D: Thelazia callipaed: infection in dogs: a new parasite for Spain. Parasi Vectors 2011, 4:148.

38. Fisa R, Gállego M, Castillejo S, Aisa MJ, Serra T, Riera C, Carrio J, Gállego J, Portus M: Epidemiology of canine leishmaniosis in Catalonia (Spain) the example of the Priorat focus. Vet Parasitol 1999, 83:87-97.

39. Moreno J, Alvar J: Canine leishmaniasis: epidemiological risk and the experimental model. Trends Parasito 2002, 18:399-405.

40. Cabezón O, Millán J, Gomis M, Dubey JP, Ferroglio E, Almeria S: Kennel dogs as sentinels of Leishmania infantum, Toxoplasma gondi, and Neospora caninu in Majorca Island, Spain. Parasitology Res 2010, 107:1505-1508.

41. Cabral M, O'Grady JE, Gomes S, Sousa JC, Thompson H, Alexander J: The immunology of canine leishmaniosis: strong evidence for a developing disease spectrum from asymptomatic dogs. Vet Parasitol 1998, 76:173-180.

doi:10.1186/1756-3305-5-60

Cite this article as: Miró et al: Current situation of Leishmania infantum infection in shelter dogs in northern Spain. Parasites \& Vectors 2012 5:60.

\section{Submit your next manuscript to BioMed Central and take full advantage of:}

- Convenient online submission

- Thorough peer review

- No space constraints or color figure charges

- Immediate publication on acceptance

- Inclusion in PubMed, CAS, Scopus and Google Scholar

- Research which is freely available for redistribution

Submit your manuscript at www.biomedcentral.com/submit 